\title{
Role In Improving Academic Supervision of Teachers' Professionalism at Sudirman II Public Elementary School Makassar
}

\author{
Ratmawati \\ Faculty of Education \\ University of Makassar \\ ratmataju@yahoo.com \\ Ardiansyah \\ Faculty of Education \\ University of Makassar
}

\author{
Andi Mappincara \\ Faculty of Education \\ University of Makassar
}

\begin{abstract}
This study aims to determine the role of the headmaster as a supervisor in the planning, implementation, and evaluation and follow-up of academic supervision in SDN Sudirman II Makassar City. The subject of this research is the headmaster and teacher of the school located in SDN Sudirman II.Objek this research is the effectiveness of the headmaster's role as supervisor in planning, implementation, follow-up and the result of Academic supervision program conducted by the headmaster. This research takes place at SDN Sudirman II Kota Makassar. The method used in data collection is interview, observation and documentation. The results showed that the role of headmaster in improving the professionalism of teachers in SDN Sudirman II has been well implemented and has been able to improve the professionalism of teachers, as evidenced by several activities conducted by the headmaster can help teachers improve the quality of process and learning outcomes. Implementation of academic supervision implementation starts from planning, implementation and follow-up of supervision so that teacher professionalism can increase. Overall the role of academic supervision can improve teacher performance in four aspects: pedagogic aspect, personality aspect, social aspect, and professional aspect. The ability of teachers can be seen in the management of learning and learning to the students as well as in the learning process is done in a pleasant atmosphere has been well done.
\end{abstract}

Keyword-supervision, academic, headmaster, teacher, professionalism.

\section{INTRODUCTION}

The government has developed various programs that are expected to improve the quality of learning that aims to improve the quality of learning through teacher performance, because teachers are human resources who determine the success of learning. Teachers are the element of education that are very close to the students in the effort of everyday education in school and much determine the success of students in achieving goals.
It is how strategic the position of teachers as professionals, in the Law of the Republic of Indonesia Number 142005 about Teachers and Lecturers, chapter III article 7 , it is mandated that the teaching profession is a special field of work carried out based on the following principles: (a) Talent, interest, calling of soul, and idealism; (b) have a commitment to improve the quality of education, faith, piety, and noble character (c) have academic qualifications and educational background in accordance with the field of duty; (d) have the necessary competencies in accordance with the task field; (e) have responsibility for the performance of professional duties; (f) earning income determined in accordance with work performance; $(\mathrm{g})$ have the opportunity to develop a sustainable professionalism with lifelong learning; (h) having guaranteed legal protection in performing professional duties; and (i) have professional organizations that have the authority to regulate matters relating to teacher professional duties. Furthermore, in the same chapter and article it is also mandated that the empowerment of the teacher profession is conducted through self-development that is democratic, fair, nondiscriminatory and sustainable by respecting human rights, religious values, cultural values, national pluralism and ethical code profession.

One of the programs that can be held in order to empower teachers is academic supervision (academic supervision). Academic supervision is a series of activities to help teachers develop their ability to manage the learning process for the achievement of academic goals. Academic supervision is an effort to help teachers develop their ability to achieve academic goals. Thus, it is essential that academic supervision is to help teachers develop their professionalism skills. Developing skills in this context should not be narrowly interpreted, merely emphasized on improving teachers' knowledge and skills, but also on commitment improvement or teacher's willingness or 
motivation because by improving the ability and motivation of teachers, academic quality will increase.

Regulation of the Minister of National Education (Permendiknas) Number 132007 on Headmaster Standards affirmed that one of the competencies that a headmaster must possess is the supervision competence. This regulation emphasizes that a headmaster must be competent in doing academic supervision of the teachers he leads.

\section{METHOD}

Based on the objectives and problems of the research, this research was classified survey research aiming to determine the implementation of a program that had been determined whether it was running as it had been established in this case was the implementation of academic supervision in improving the professionalism of teachers at SDN Sudirman II Makassar. The approach chosen in this research was descriptive qualitative approach. This research was focused on the headmaster in the implementation of academic supervision from planning, implementation to follow up by headmasters to improve the quality of learning process. The subjects of this study were headmaster, and teacher of SDN Sudirman II. Data collection technique was done by interview, observation and documentation by using research instrument in the form of: interview guides, observation guidance and documentation as complementary instrument of data analysis technique done by data occupying first, then done by presenting data. If any data was not yet valid then it was reduced again, and if it was valid all proceed with decision making or data verification and data validation.

\section{RESULTS AND DISCUSSION}

The academic supervision of the headmaster of SDN Sudirman II has been conducted periodically and incidentally. Implementation of periodic supervision has been performed indicated from the data of supervision implementation result through checking the learning device files such as lesson plan (RPP). And the implementation of incidental supervision conducted by controlling the class in an unprogrammed way, it is done by checking the classes during the lesson in progress all at once to control the teacher's discipline in doing the learning process.

The realization of the supervision conducted by the headmaster of SDN Sudirman II is done to directly control all teachers in performing their duties and functions as educators in the school. The process of conducting headmaster academic supervision is carried out in several aspects ranging from planning, implementation, follow-up and the results of supervision implementation aimed at improving the professionalism of teachers SDN Sudirman II starting from:

\section{A. Supervision Program Planning}

The supervision program planning has been well implemented by the headmaster of SDN Sudirman II, but it has not been implemented maximally because the planning arranged in the supervision program only contains the schedule of supervision without performing various preparations either internally or externally. But internally the headmaster before doing Supervision has set up supervision plans such as the implementation schedule of supervision in a very simple form, has not included the broader program plan as it should and has not been done in detail and systematic. And preparation of external supervision prepared by other parties to facilitate the successful implementation of supervision has not been implemented by the headmaster of SDN Sudirman II Makassar City.

The planning of supervision program is important for the headmaster so that the component to be supervised from the teacher can be done more focused, in the planning also explains how the supervision process is done, how the processing and follow-up of the supervision result is done in detail and systematic because good supervise planning very determine success Improving the quality of teacher learning. Urgency of academic supervision program planning is a guideline used as a scheme or guidance for the headmaster to supervise so that teachers can develop their ability to manage the learning process so that the goal of learning can be achieved

\section{B. Implementation of Supervision}

Implementation of supervision conducted by the headmaster is done well both periodically and incidentally. Periodically, the supervision performed by the headmaster is shown by checking the learning plan and done once in a semester. Incidental supervision is always done by the headmaster to control classroom and teacher discipline in teaching. The realization of the academic supervision done by the headmaster in SDN Sudirman II is done, the supervision is done directly by the headmaster to see the teaching and learning activities of teachers in the classroom, and the supervision conducted by the headmaster is done by informing each teacher about the supervision schedule to them. This goal is done so that every teacher has readiness in the learning process.

Implementation of academic supervision conducted by the headmaster includes several aspects ranging from pre- 
observation, observation and post-observation. Preobservation by the headmaster to see the preparation / willingness of teachers in the teaching process that begins by looking at the preparation of teacher learning tools in teaching. Pre-observation activities conducted to see the readiness of teachers or teacher learning tools before performing academic supervision.

The next stage is the observation, at this stage, the headmaster observes the ongoing learning process. From the observations made by the researcher conducted the observation of headmaster in class III A It appears that the headmaster focuses on observing the ongoing learning process in the classroom both the observations made by the teacher and the learning activities undertaken by the students in addition also to fill in the observation guidelines used as a device Supervision that contains some aspects of the assessment related to the conduct academic supervision

The final stage in the implementation of supervision is post-observation. At this stage, the headmaster with the teacher has an agreement to discuss the observations, the guidance done by the headmaster in post-observation is related in administration such as RPP, relevance of material with approach, and media utilization.

In the post-observation stage of the academic supervision conducted by the headmaster focuses on the suitability of the learning process with the planning, the good and the less good thing, the achievement of learning goals, the difficulties of students, the difficulties of teachers, alternative solutions to overcome student and teacher difficulties, Mutual consent on the upgrading and development program to be undertaken, and affirmation for further improvement and learning development. From the overall data and information information in the form of teacher answers obtained then the headmaster can provide advice and input by writing an agreement on the program improvement and development in the advice and input.

\section{Follow Up of Academic Supervision}

After all the activities are done, both Pre Observation, Observation and Post Observation, then the next step is to recapitulate the results of supervisi. to recap all the results supervisi so the headmaster follow-up supervision results. Based on the conclusions of the special note of the headmaster conducted formulation of follow-up results Supervise it by asking the teacher to: revise the RPP and its teaching materials; Reorganize teacher learning strategies with more effective exploration, elaboration and confirmation activities by consulting with more experienced senior teachers. The results of consultation meetings with senior teachers and the revised results of the RPP and their teaching materials are reported as activities for the realization of the follow-up of supervision results.

There are many ways to follow-up supervisory outcomes such as mentoring by senior teachers, by the headmaster; It could be by conducting IHT or training or workshop; or it could be with special consideration for example because the teacher's problem also happened to the other teacher. The conclusion that can be drawn from the implementation of academic supervision conducted by the headmaster is the focus of supervision that is technical skills in learning.

As a final conclusion, the following synthesis reminds us that scoring in academic supervision is a tool for critiquing and finding problems for improvement programs and teacher performance improvement, not the ultimate goal of academic supervision. Supervise is to observe and to direct. Before the performance is improved and before the followup of the supervision result is realized, then the academic supervision has not been completed because the academic supervision is able to improve the performance of the teacher, so do not stop doing academic supervision in the school. Therefore, the headmaster must be sure that the academic supervision will make the teacher appear better in teaching than usual, and make teachers more ready to teach because of academic supervision conducted by the headmaster as a key achievement of quality learning.

Every component in academic supervision, from function to goal must be done continuously in order to have a positive impact on teacher performance. This will be seen in the real change of teacher performance in implementing the learning process in the classroom. If observed on a longterm scale, it will be able to show the role of academic supervision conducted by the headmaster

Academic supervision by headmaster to teachers in terms of administration and teaching methods and other aspects will influence and encourage teachers to perform better in every performance in teaching. This will be seen in the process of preparation and implementation of teaching conducted by a teacher, as well as in terms of administration. In terms of mastery of the media, through supervision will also provide encouragement and motivation for teachers as educators to master the media learning and mastery and development of materials that are harmonized with the development of science.

The success of academic supervision can be seen from the improvement of teacher performance in terms of teacher skill in performing their main duty and responsibility in 
implementing learning. This effort has been done by the school in various ways to raise the quality of learning through supervision. Improving the quality of learning will affect the quality of educational that can improve the quality of student knowledge as the object and subject of education. And the most decisive stage in the implementation of academic supervision of the headmaster, is the evaluation, because the evaluation is expected to improve the preparation of teachers in preparing everything that become the duty and responsibility. It includes discipline, learning plan, and learning process. If necessary, we can also give a reprimand to the teacher so supervision can improve the professionalism of teachers in learning.

Teachers are always required to be able to teach professionally and always improve teaching methods and strategies in the classroom, tailored to the characteristics of learners. The implementation of academic supervision conducted by the headmaster of SDN Sudirman II refers to aspects that a teacher must have in improving professionalism on pedagogic aspects, personality aspects, social aspects, and professional aspects

\section{1) Pedagogic Aspects}

Management of learning and learning achievement to students has been done well by teachers in SDN Sudirman II because this management aims to support the activities in the delivery of learning to the students. To be able to master these aspects done by teachers through self-development and deepen things related to the device Learning and this is done as a form of coaching from the implementation of academic supervision.

The results of the observations made in this research show that the pedagogic ability of the teacher is good because the teacher has understood the insight and the foundation of education, understanding to learners, curriculum development / syllabus, designing the learning, the implementation of educational and dialogical learning, the utilization of learning technology, And the development of learners to actualize their potential, It's done well. In the process of learning also has seen a good relationship between teachers to students in interpersonal relationships and in learning creates a family climate so the students are not ashamed to ask the teacher about the material that is not clear.

From the result of the implementation of academic supervision conducted by the headmaster to the teacher shows optimal results. This can be seen from the evaluation of learning outcomes at each meeting both at the beginning of learning in the form of apperception, the learning process and the end of the learning process in class has been done by almost all teachers of SDN Sudirman II.

\section{2) Aspect of Personality}

Teacher personality competence becomes a very important factor because the teacher will become a figure to be imitated by the students. The behavior and attitudes of the teacher should be an example for the students. The results of observations made by researchers on aspects of personality is very good it is shown from the indicators of the attitude of faith and piety, noble character, show the attitude of wise and prudent, democratic, stable, dignified, stable attitude, adult, honest, Students, objective in performing their own performance evaluation, as well as self-development.

Based on the results of obeservasion conducted shown some indicators that indicate aspects of the personality, the average of all teachers shown with good and balanced results. There are no significant results that strikingly occur

\section{3) Social Aspects}

The ability of the teacher's social aspect will affect the relationship with the community around the relationship and good communication to the community, to the parents of the students, will create a supportive atmosphere by teachers and students that will also impact on the readiness and support of classroom learning. Students and teachers will understand and mutually adjust the lessons.

Social capacity has been well done. It can be seen from the indicators of intensive communication to all stakeholders of education, using communication technology, communication with peers and general, socializing with the community, applying the principles of brotherhood and spirit of togetherness, inclusive, objective and discriminative.

The achievement of some indicators above done by SDN Sudirman II teacher showed average balanced result there are no some indicators that are not realized. Based on the results of observations conducted by researchers said that it is good, to see that teachers show good communication to all the elements that There are both students, fellow educators, parents or guardians and also with the community. A friendly and sympathetic attitude is shown by some teachers to their students with the aim of being morally encouraged to students to be more willing to improve their learning conditions. 


\section{4) Professional Aspects}

Competence in the professional aspect means the teachers ability in the mastery of learning materials widely and deeply mastered by the teacher as a condition of support in the delivery of learning. Indicators of professional teacher ability in this aspect is the ability of concepts, structures and methods coherent with teaching materials, teaching materials are in the school curriculum, the relationship between the concept of related subjects, the application of scientific concepts in daily life, competition professional In a global context with still maintaining national values and culture.

Data from the observations that have been done by researcher with that indicators above can be said well, that shown from the material taught in accordance with syllabus and curriculum applied in Sudirman II. Other indicators are also shown with balanced result and there is nothing significant differences in result.

The results of observations conducted by researcher to some teachers in SDN Sudirman II showed from four aspects observed to get results for pedagogic aspects are still in the good category, personality aspects in the excellent category, social aspects in excellent category and professional aspects in good category.

\section{CONCLUSION}

The role of headmaster academic supervision in improving teachers' professionalism at SDN Sudirman II had been optimally implemented starting from the planning, implementation and follow-up of supervision implementation.

a. The planning of the supervision program had been well implemented by the headmaster of SDN Sudirman II, but had not been implemented maximally because the planning arranged in the supervision program only contains the schedule of supervision implementation alone without performing various preparations either internally or externally.

b. Supervision implementation conducted by the headmaster was performed well periodically or incidentally and performed according to the schedule of supervision implementation once in one semester and done with the stages of preobservation, observation and post-observation.

c. The follow up of the Academic Supervision Implementation conducted by the headmaster of SDN Sudirman II had been done maximum where this can be seen from the special note given on the supervision instrument format and teacher supervision books starting from pre observation, observation, and post observation. 